\title{
Diagnostic Evaluation and Uncertainty Quantification of Earth and Environmental Systems Models
}

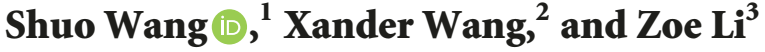 \\ ${ }^{1}$ Department of Land Surveying and Geo-Informatics, Hong Kong Polytechnic University, Kowloon, Hong Kong \\ ${ }^{2}$ School of Climate Change and Adaptation, University of Prince Edward Island, Charlottetown, Canada \\ ${ }^{3}$ Department of Civil Engineering, McMaster University, Hamilton, Canada \\ Correspondence should be addressed to Shuo Wang; shuo.s.wang@polyu.edu.hk
}

Received 19 November 2018; Accepted 20 November 2018; Published 2 December 2018

Copyright (c) 2018 Shuo Wang et al. This is an open access article distributed under the Creative Commons Attribution License, which permits unrestricted use, distribution, and reproduction in any medium, provided the original work is properly cited.

Earth and Environmental Systems (EES) models play a crucial role in facilitating the research and development in science and engineering disciplines. To better conceptualize the EES by using mathematical equations, models are becoming more complex with increasingly more sources of uncertainty, including the characterization of initial and boundary conditions, the errors in observation data, the difficulty in obtaining accurate parameter estimates, and model structural deficiencies. Therefore, it is necessary to address complexities and uncertainties propagated through the EES models in order to advance the understanding of nonlinear dynamics and chaos in the EES and to enhance the reliability of model results.

The aim of this special issue is to gather contributions on both theory and application of diagnostic analysis and uncertainty quantification of the EES models. Researchers and scientists are invited to propose recent advances in methodologies, models, and tools for solving complex engineering problems. This special issue has received a total of 27 manuscripts, 10 of which have been accepted for publication. The accepted papers involve a variety of modelling techniques and contribute to a wide range of application areas. A brief introduction for each contribution is provided as follows.

The paper entitled "Planning of Electric Power Systems Considering Virtual Power Plants with Dispatchable Loads Included: An Inexact Two-Stage Stochastic Linear Programming Model" by C. Zhou et al. proposes an inexact two-stage stochastic linear programming method for supporting sustainable management of electric power systems under uncertainty. The proposed method is applied to solve a typical planning problem of power systems considering virtual power plants.

The paper entitled "Inexact Fuzzy Chance-constrained Fractional Programming for Sustainable Management of Electric Power Systems" by C. Y. Zhou et al. presents an inexact fuzzy chance-constrained fractional programming model for the planning of electric power systems under uncertainty. The proposed model can not only deal with multiple uncertainties but also tackle potential tradeoffs between conflicting objectives in terms of greenhouse gas mitigation and profit maximization.

The paper entitled "Connectivity Evaluation and Planning of a River-Lake System in East China Based on Graph Theory" by J. Chen et al. introduces a connectivity evaluation index method based on graph theory. The proposed method is applied for evaluating the connectivity of the stream network and for planning a river-lake system located in Eastern China.

The paper entitled "A Tidal Level Prediction Approach Based on BP Neural Network and Cubic B-Spline Curve with Knot Insertion Algorithm" by W. Wang and H. Yuan introduces a new method that merges the strengths of the $\mathrm{BP}$ neural network and the cubic B-spline curve with the knot insertion algorithm for predicting the tide levels of storm surge caused by typhoons. The predictive performance is 
validated against historical tide level and typhoon data at Luchaogang, China.

The paper entitled "Application of Surface Spline Interpolation Method in Parameter Estimation of a $\mathrm{PM}_{2.5}$ Transport Adjoint Model" by N. Li et al. proposes a new method for estimating initial conditions in a $\mathrm{PM}_{2.5}$ transport adjoint model. The field of initial conditions is constructed by interpolating values at independent points using the surface spline interpolation method. The adjoint model combined with the surface spline interpolation is evaluated for optimizing initial conditions of the $\mathrm{PM}_{2.5}$ transport simulation.

The paper entitled "Economic and Environmental Effects of Public Transport Subsidy Policies: A Spatial CGE Model of Beijing" by P. Xu et al. proposes a Spatial Computable General Equilibrium (SCGE) model to examine the economic and environmental effects of public transport subsidy policies. By using a benchmark equilibrium calibrated for Beijing, the SCGE model is used to simulate social welfare, population distribution, and travel-related $\mathrm{CO}_{2}$ emission effects under different subsidy policies, including fare subsidy, cash grant, road expansion, and public transport speedup.

The paper entitled "Study on Viscoelastic Deformation Monitoring Index of an RCC Gravity Dam in an Alpine Region Using Orthogonal Test Design" by Y. Huang and Z. Wan presents a new method for determining viscoelastic deformation monitoring index of a Roller-compacted concrete (RCC) gravity dam in an alpine region. The state of viscoelasticity for the dam is illustrated followed by an investigation and designation of adverse load cases using the orthogonal test method. Water pressure component is then calculated by the finite element method, while temperature, time effect, and frost heave components are obtained through a deformation statistical model.

The paper entitled "A Complete MCDM Model for NPD Performance Assessment in An LED-Based Lighting Plant Factory" by W.-C. Chen et al. proposes a hybrid multicriteria decision-making model for assessing the performance of the new product development in the light-emitting diode- (LED) based lighting plant factory. The feasibility of the proposed model is validated in a Taiwanese LED-based lighting plant factory.

The paper entitled "Effect of Shaft Pillar Extraction on Stability of Main Shaft: A Case Study at Xincheng Gold Mine, China" by X. Liu et al. presents a comprehensive investigation on the effects of mining activates on the stability of the main mine shaft at the Xincheng Gold Mine in China by means of in situ monitoring and numerical simulation. This study is useful for achieving reasonable predictions of shaft deformation and for providing valuable suggestions to mining operations.

The paper entitled "Analytical Solution and Application for One-Dimensional Consolidation of Tailings Dam" by $\mathrm{H}$. Liu et al. proposes a partial differential equation for reasonably estimating the pore water pressure based on the assumption of $1 \mathrm{D}$ consolidation and small strain of tailings material. The analytic solutions can be obtained by solving the partial differential equation, which is useful for providing meaningful insights into the stability of the tailings dam.
We hope that the readers will find this special issue interesting and the published papers will stimulate further advancement in diagnostic evaluation and uncertainty quantification of Earth and Environmental Systems Models.

\section{Conflicts of Interest}

We declare that there are no conflicts of interest regarding the publication of this editorial.

\section{Acknowledgments}

We would like to express our gratitude to all the authors for their contributions and also the reviewers for their efforts to provide valuable comments and feedback.

\section{Shuo Wang}

Xander Wang

Zoe Li 


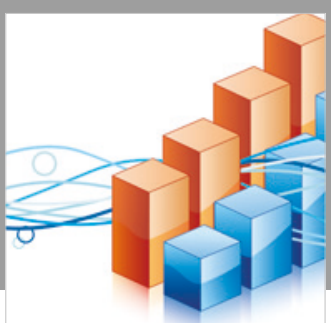

Advances in

Operations Research

\section{-n-m}
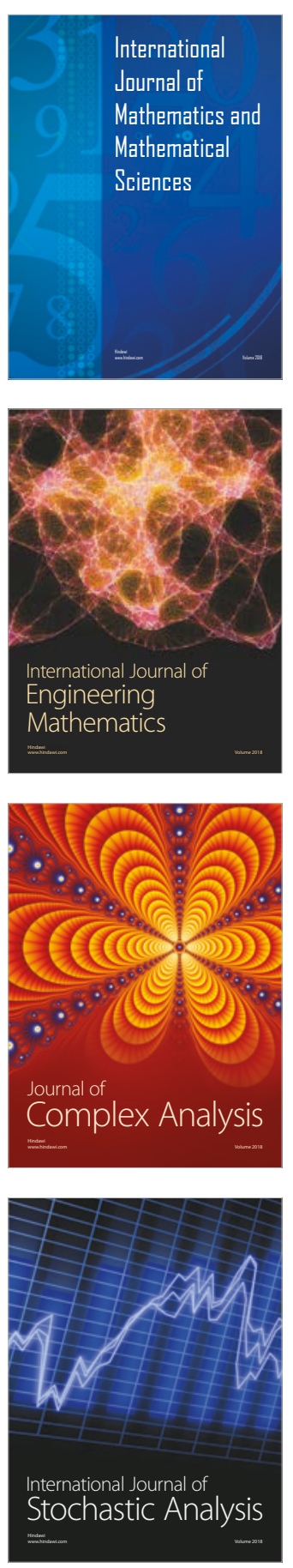
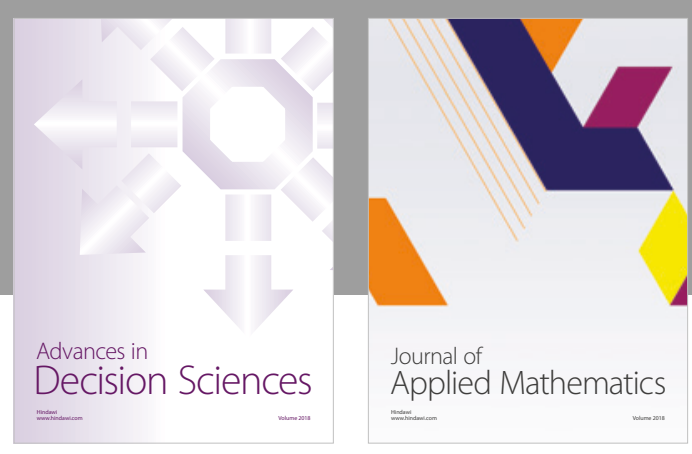

Journal of

Applied Mathematics
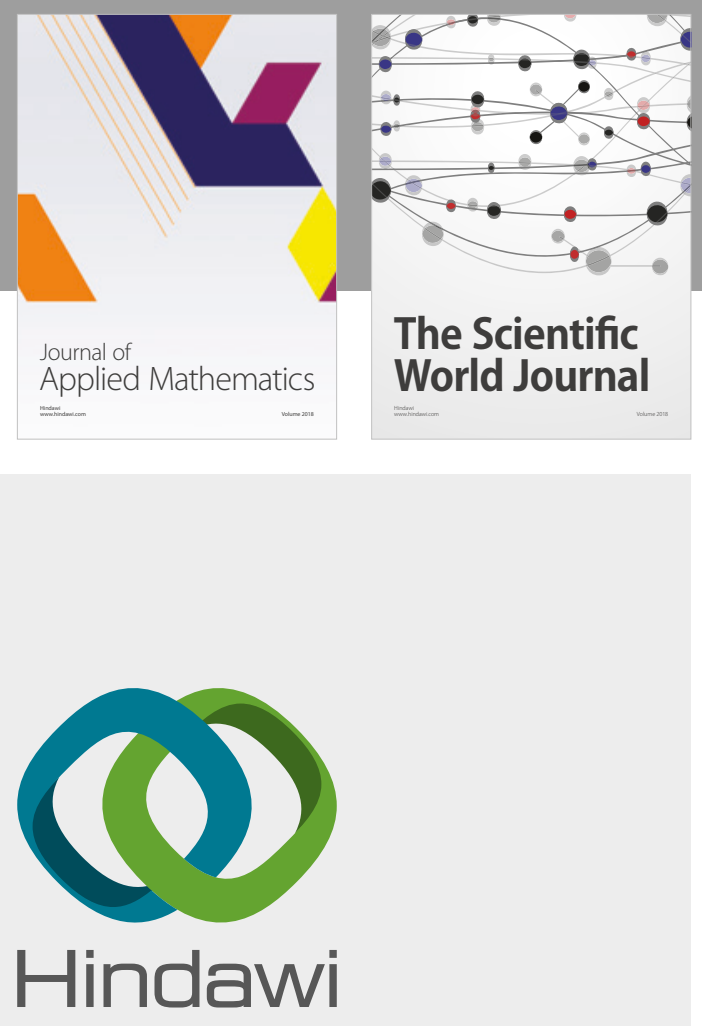

Submit your manuscripts at

www.hindawi.com

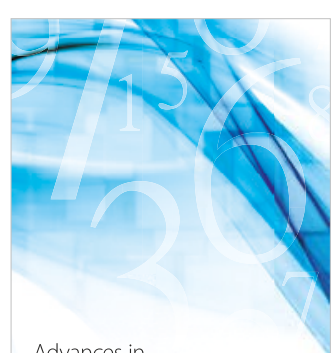

Advances in
Numerical Analysis
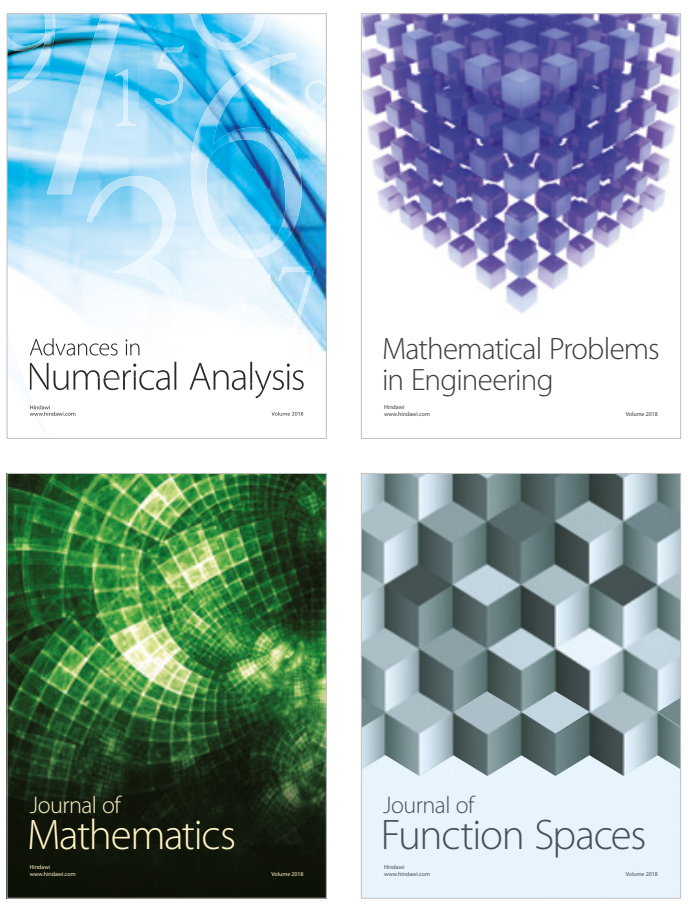

Mathematical Problems in Engineering

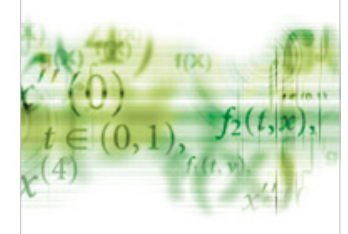

International Journal of

Differential Equations

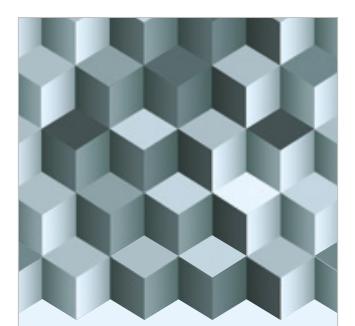

Journal of

Function Spaces

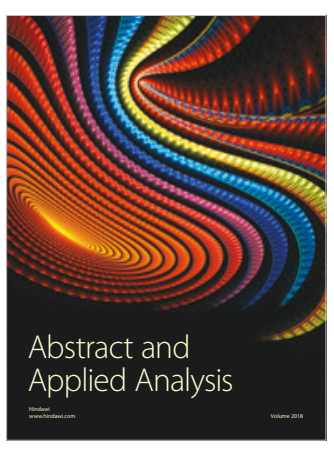

The Scientific

World Journal



Journal of

Probability and Statistics
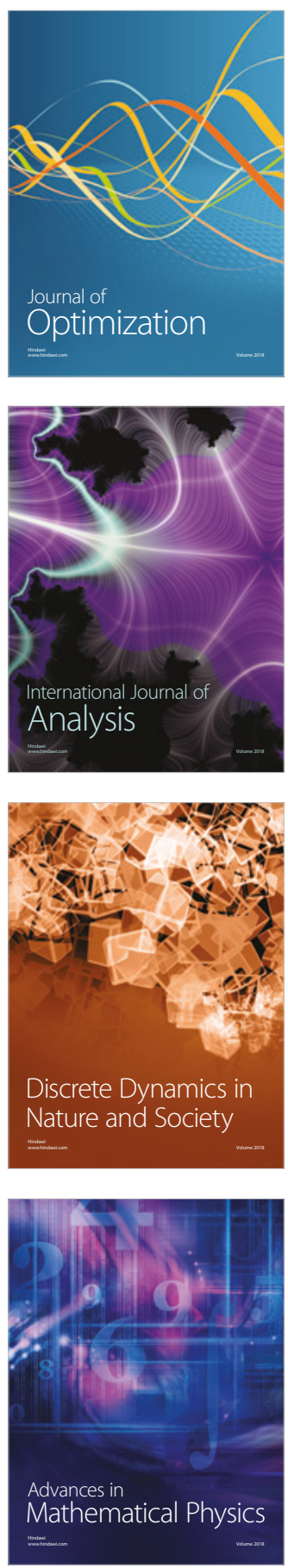